Jármai,K.,Farkas,J.,Uys,P.: Optimum design and cost calculation of a simple frame with welded or bolted corner joints, Welding in the World, Vol. 48. 2004, No. 1-2. pp. 42-49. ISSN 0043-2288

\title{
Optimum design and cost calculation of a simple frame with welded or bolted corner joints
}

\author{
Jármai,K. ${ }^{1}$, Farkas,J. ${ }^{1}$, Uys,P. ${ }^{2}$ \\ ${ }^{1}$ University of Miskolc, Hungary, ${ }^{2}$ University of Pretoria, South Africa
}

\begin{abstract}
A one bay one storey steel planar frame is constructed from rolled I-profile elements consisting of universal columns and a universal beam. The buckling strengths of the columns and beam according to Eurocode 3 (2002) constitute the design constraints. The beam and column profiles are optimised to minimize the structural mass subject to the design constraints for both a flush-endplate bolted (semi-rigid) structure and a welded (rigid) structure. For the specific numerical case considered the structure is subject to a horizontal force and a uniformly distributed vertical load. Comparing the costs of these optimal solutions, shows that the bolted frame is $7 \%$ or $14 \%$ cheaper than the welded frame on the base of British and South African cost data respectively.
\end{abstract}

\section{IIW-Thesaurus keywords:}

welded structures, frames, semi-rigid joints, bolted connections, cost calculation, frame stability

IIS/IIW- (ex.doc. XV-1145-03) recommended for publication by IIW Commission XV "Design, analysis and fabrication of welded structures"

\section{Introduction}


Steel frames can be constructed using either welded or bolted connections. Welded joints are rigid, while the behaviour of bolted joints is semi-rigid, since the local displacements of joint components cause an additional angle deformation of corner connections. The rigidity of a beam-to-column frame connection is characterized by the diagram bending moment versus angle deformation as given in [1]. According to [2] welded connections generally fulfil the requirements for rigid rotational stiffness.

The additional rotations affect the bending moments, normal and shear forces in frame members and the frame stability. Thus, this effect should be taken into account in the frame optimization as well.

In a previous study [3, 4] the cost differences between welded and bolted beam-to-column connections were shown and also how the economics of structures are influenced by the differences in bending moments and shear forces. The aim of the present study is to investigate these differences in the case of a simple planar sway frame and also to determine the optimum design of the frame in the case of welded as well as bolted connections. This is a relevant issue since single story sway frames constitute the basic buildings units of structures such as warehouses, portal cranes, supporting frames for pressure vessels, vehicle structures.

The optimum design of frames with semi-rigid joints has been dealt with by several authors e.g. AlSalloum \& Almusallam [5], Simões [6], Kameshki \& Saka [7]. The difficulty of the optimization is that the additional angle deformation depends on many parameters (such as the type of bolted connection, elongation of bolts and local displacements of plate elements of connected profiles). Thus, the bending moments depend on unknown profile dimensions. To ease the optimization procedure the guess formula for the joint stiffness proposed by Steenhuis et al.[8] is used here.

Another problem is that available rolled I-section rods have to be used. These present a discrete range of profiles which are listed by manufacturers in tabulated form, e.g. universal beams (UB) and columns (UC) (as given by ARBED catalogue of structural shapes [9]). The characteristics of these profiles (cross-sectional area, moments of inertia etc.) depend on main section dimensions and it is difficult to calculate them as simple functions, which is required for optimization purposes. For this reason approximate functions determined by curve-fitting selection using only one variable (profile height) are used. 
The optimization of a welded as well as a bolted frame is performed using the structural volume as objective function to be minimized, and the costs are calculated and compared to each other. British and South-African cost data are used.

\section{Forces and bending moments in the frame}

We investigate a one-storey one-bay sway (unbraced) frame shown in Figure 1. loaded by a uniformly distributed vertical load of intensity $p$ and a concentrated horizontal force $F$. The corner bending moment $M_{p}$ (Fig.2) is derived from an angle deformation equation as follows.

The angle deformation of the beam due to load $p$ (Fig.3) is

$$
\varphi_{0}=\frac{p L^{3}}{24 E I_{2}},
$$

and due to the bending moments

$$
\varphi_{1}=\frac{M_{p} L}{2 E I_{2}},
$$

where $E$ is the elastic modulus and $I_{2}$ is the moment of inertia of the beam section. The angle deformation of the column end due to the bending moment $M_{p}$ and reactive force $N_{p 2}=3 M_{p} /(2 H)$ is

$$
\varphi_{2}=\frac{M_{p} H}{4 E I_{1}},
$$

where $I_{l}$ is the moment of inertia of the column section. The angle deformation equation, considering the angle difference caused by the semi-rigid connection of stiffness $S_{j}$, is

$$
\varphi_{0}-\varphi_{1}-\varphi_{2}=\theta=\frac{M_{p}}{S_{j}}
$$

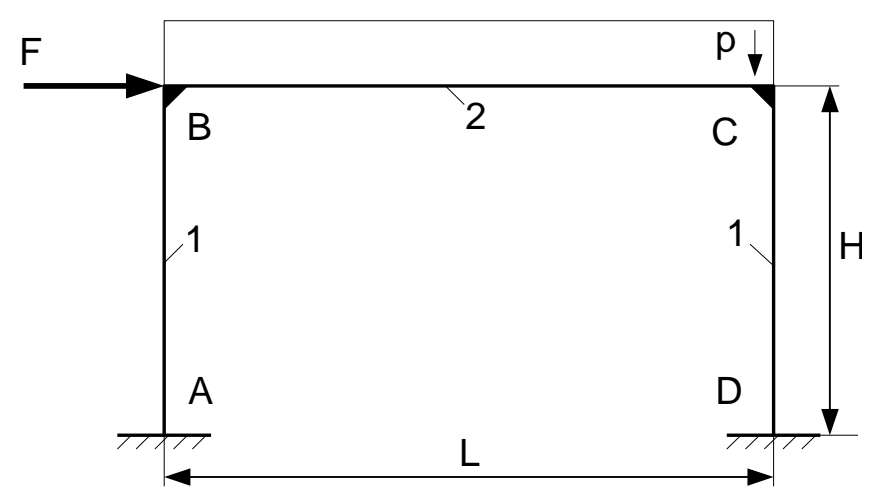

Figure 1. Unbraced planar frame

From Eq.(4) one obtains 


$$
M_{p}=\frac{p L^{2}}{24} \cdot \frac{1}{\frac{1}{2}+\frac{H I_{2}}{4 L I_{1}}+\frac{E I_{2}}{L S_{j}}}
$$

Note that for welded (rigid) joints $S_{j} \rightarrow \infty$ and the third member in the denominator becomes zero.
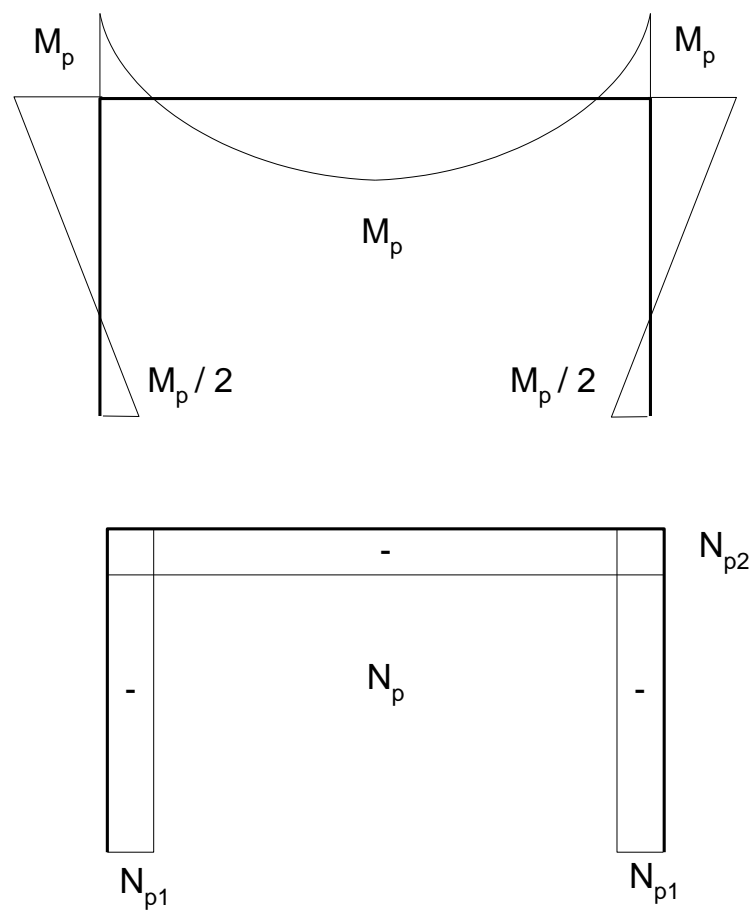

Figure 2. Diagrams of bending moments and axial forces

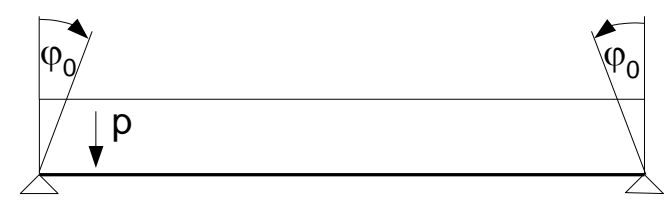

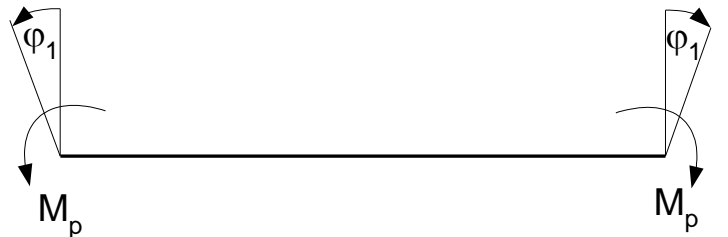

(a)

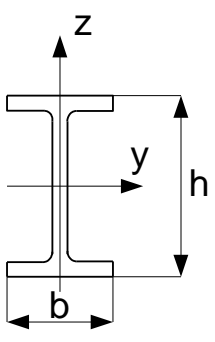

(b)

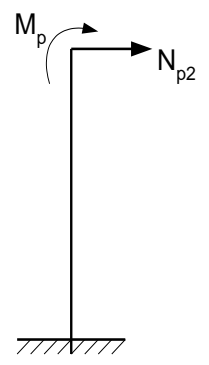

(c)

Figure 3. (a) Angle deformations of the beam due to uniform normal load. (b) The main dimensions of a rolled I-beam. (c) Bending moment and horizontal force acting on a column 
Similarly, the corner bending moments due to the horizontal force $F$ (Fig.4) can be calculated considering the following angle deformation in the beam due to $M_{F}$ (Fig.5):

$$
\varphi_{M F}=\frac{M_{F} L}{6 E I_{2}}
$$

and the angle deformations of the column top due to $F / 2$ and $M_{F}$ are

$$
\frac{F H^{2}}{4 E I_{1}}-\frac{M_{F} H}{E I_{1}},
$$
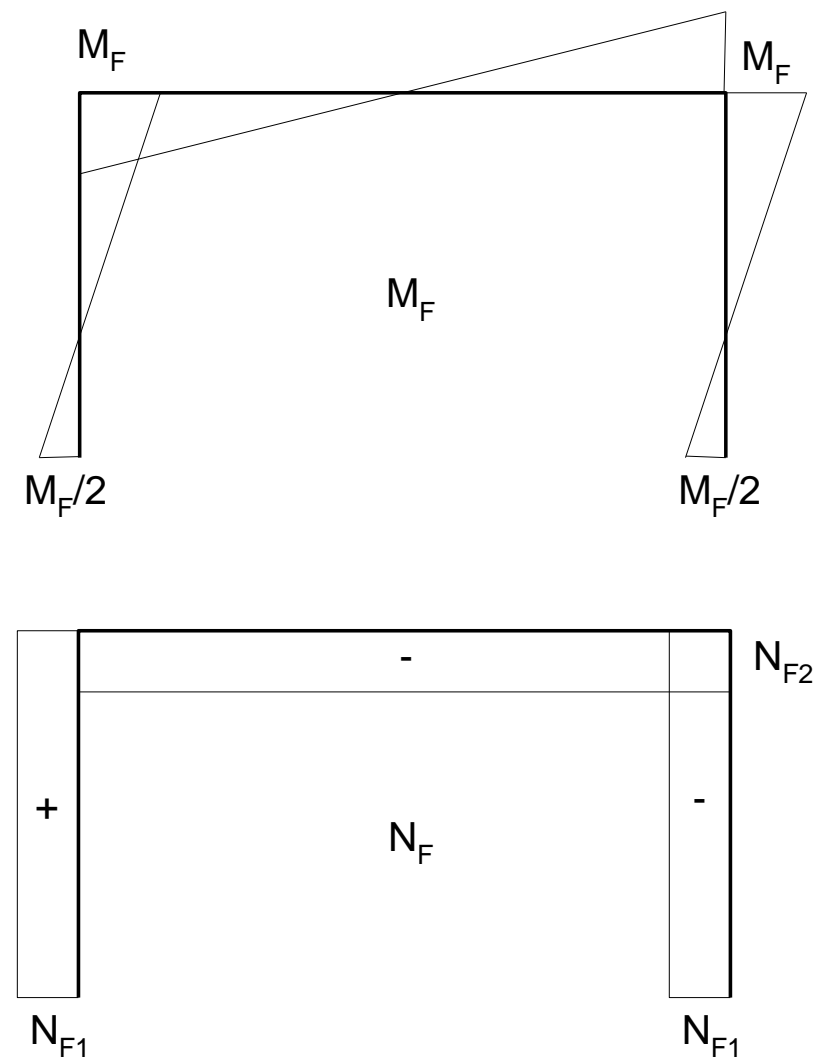

Figure 4. Bending moments and axial forces due to the horizontal force $F$

Considering also the angle difference caused by semi-rigid joints, the angle equation can be expressed as

$$
\frac{F H^{2}}{4 E I_{1}}-\frac{M_{F} H}{E I_{1}}=\frac{M_{F} L}{6 E I_{2}}+\frac{M_{F}}{S_{j}} .
$$

From Eq. (8) it follows that

$$
M_{F}=\frac{F H}{4} \cdot \frac{1}{1+\frac{L I_{1}}{6 H I_{2}}+\frac{E I_{1}}{H S_{j}}} .
$$



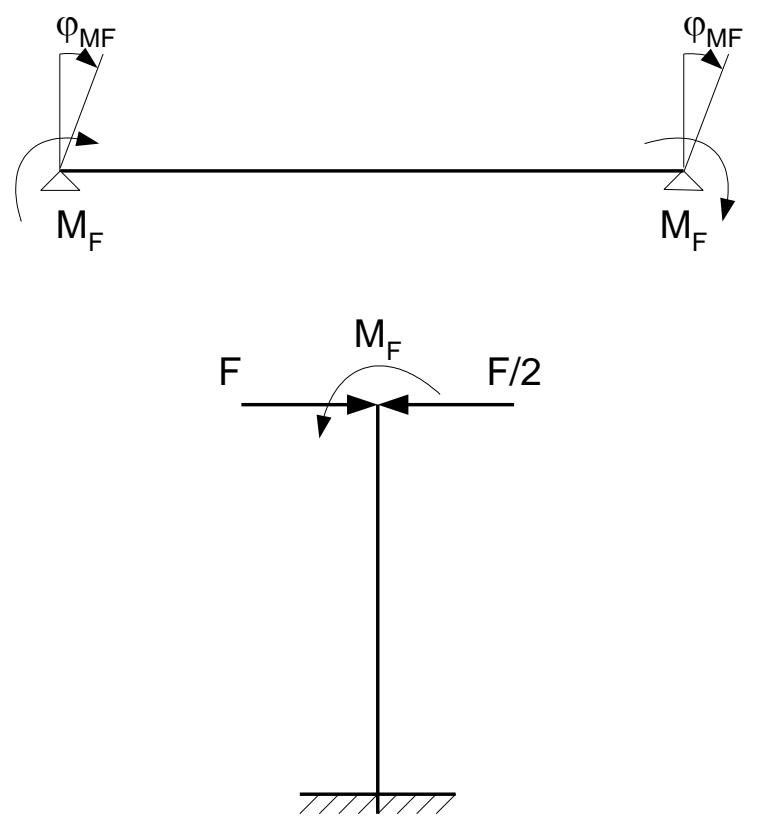

Figure 5. Angle deformations of the beam due to horizontal force $F$. Bending moment and horizontal forces acting on the columns in the case of the horizontal load $F$

\section{Design constraints}

The columns and the beam are loaded by bending and an axial force. Since rolled I-section rods are used, these should fulfil the constraints on combined bending and compression to avoid overall flexural and torsional buckling as well as lateral-torsional buckling. These stress constraints are formulated according to Eurocode 3 (2002) (EC3) [10].

\subsection{Bending and axial compression constraint of the column CD}

The buckling constraint about the $y$-axis (Fig.3) requires that:

$$
\frac{N_{1}}{\chi_{y 1} f_{y 1} A_{1}}+k_{y y 1} \frac{M_{C}}{\chi_{L T 1} f_{y 1} W_{y 1}} \leq 1,
$$

and for buckling about $z$-axis

$$
\frac{N_{1}}{\chi_{z 1} f_{y 1} A_{1}}+k_{z y 1} \frac{M_{C}}{\chi_{L T 1} f_{y 1} W_{y 1}} \leq 1
$$

where $f_{y 1}=f_{y} / \gamma_{M 1} ; \gamma_{M 1}=1.1, f_{y}$ is the yield stress, $\gamma_{M 1}$ is the partial safety factor. 


$$
N_{1}=\frac{p L}{2}+\frac{2 M_{F}}{L}
$$

and the bending moment is calculated as

$$
M_{C}=M_{p}+M_{F} .
$$

The overall buckling factor for the $y$-axis is

$$
\chi_{y 1}=\frac{1}{\phi_{y 1}+\sqrt{\phi_{y 1}^{2}-\bar{\lambda}_{y 1}^{2}}},
$$

where

$$
\begin{aligned}
& \phi_{y 1}=0.5\left[1+\alpha_{y 1}\left(\bar{\lambda}_{y 1}-0.2\right)+\bar{\lambda}_{y 1}^{2}\right], \\
& \alpha_{y 1}=0.21 \quad \text { if } \quad h_{1} / b_{1}>1.2, \\
& \alpha_{y 1}=0.34 \quad \text { if } \quad h_{1} / b_{1} \leq 1.2, \\
& \bar{\lambda}_{y 1}=\frac{K_{1} H}{r_{y 1} \lambda_{E}} ; K_{1}=2 ; r_{y 1}=\sqrt{\frac{I_{y 1}}{A_{1}}} ; \lambda_{E}=\pi \sqrt{\frac{E}{f_{y}}} .
\end{aligned}
$$

and

According to Steenhuis et al. [8] the joint stiffness for a bolted joint with a flush end plate and cover plate (Fig.6) can be approximated by the following formula

$$
S_{j}=\frac{E z^{2} t_{f c}}{11.5}
$$

where $t_{f c}$ is the column flange thickness and $z$ is the arm of the bending forces in the joint, which is approximately equal to the web height, $z=0.55 h_{2}$.

Furthermore

$$
k_{y y 1}=0.9\left(1+0.6 \bar{\lambda}_{y 1} \frac{N_{1}}{\chi_{y 1} f_{y 1} A_{1}}\right) \leq 0.9\left(1+0.6 \frac{N_{1}}{\chi_{y 1} f_{y 1} A_{1}}\right) .
$$

where $k_{\mathrm{yy} 1}$ parameter considers the secondary effects, the interaction between compression and bending.

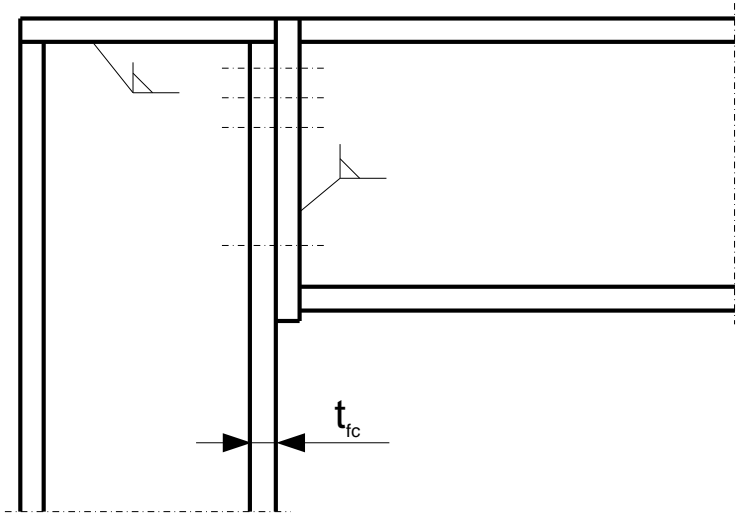

Figure 6. Bolted connection with flush-end plate 
The lateral-torsional buckling factor is

$$
\chi_{L T 1}=\frac{1}{\phi_{L T 1}+\sqrt{\phi_{L T 1}^{2}-\bar{\lambda}_{L T 1}^{2}}},
$$

with

$$
\begin{array}{ll}
\phi_{L T 1}=0.5\left[1+\alpha_{L T 1}\left(\bar{\lambda}_{L T 1}-0.2\right)+\bar{\lambda}_{L T 1}^{2}\right], \\
\bar{\lambda}_{L T 1}=\sqrt{\frac{W_{y 1} f_{y}}{M_{c r 1}}} \\
M_{c r 1}=1.132 \pi^{2} E \frac{I_{z 1}}{H} \sqrt{\frac{I_{\omega 1}}{I_{z 1}}+\frac{H^{2} G I_{t 1}}{\pi^{2} E I_{z 1}}} \\
\alpha_{L T 1}=0.34 \quad \text { if } \quad \text { if } & h_{1} / b_{1} \leq 2 \\
\alpha_{L T 1}=0.49 & h_{1} / b_{1}>2
\end{array}
$$

The overall buckling factor for $z$-axis is

$$
\begin{aligned}
& \chi_{z 1}=\frac{1}{\phi_{z 1}+\sqrt{\phi_{z 1}^{2}-\bar{\lambda}_{z 1}^{2}}} \\
& \phi_{z 1}=0.5\left[1+\alpha_{z 1}\left(\bar{\lambda}_{z 1}-0.2\right)+\bar{\lambda}_{z 1}^{2}\right] \\
& \bar{\lambda}_{z 1}=\frac{K_{1} H}{r_{z 1} \lambda_{E}} ; K_{1}=2 ; r_{z 1}=\sqrt{\frac{I_{z 1}}{A_{1}}} \\
& \alpha_{z 1}=0.34 \quad \text { if } \quad h_{1} / b_{1}>1.2 \\
& \alpha_{z 1}=0.49 \quad \text { if } \quad h_{1} / b_{1} \leq 1.2 \\
& k_{z y}=1-\frac{0.05 \bar{\lambda}_{z 1}}{C_{m L T 1}-0.25} \cdot \frac{N_{1}}{\chi_{z 1} f_{y 1} A_{1}} \geq 1-\frac{0.05}{C_{m L T 1}-0.25} \cdot \frac{N_{1}}{\chi_{z 1} f_{y 1} A_{1}} \\
& C_{m L T 1}=C_{m y 1}^{2} \frac{a_{L T 1}}{\sqrt{\left(1-\frac{N_{1}}{\chi_{z 1} f_{y 1} A_{1}}\right)\left(1-\frac{N_{1}}{N_{c r T 1}}\right)}} \\
& C_{m y 1}=C_{m y .01}+\left(1-C_{m y .01}\right) \frac{\sqrt{\varepsilon_{y 1}} a_{L T 1}}{1+\sqrt{\varepsilon_{y 1}} a_{L T 1}} \\
& \varepsilon_{y}=\frac{M_{C} A_{1}}{W_{y 1} N_{1}} ; \quad a_{L T 1}=1-\frac{I_{t 1}}{I_{y 1}} \\
& C_{m y .01}=0.79+0.21 \psi_{1}+0.36\left(\psi_{1}-0.33\right) \frac{N_{1}}{\chi_{z 1} f_{y 1} A_{1}} ; \quad \psi_{1}=-0.5
\end{aligned}
$$

The elastic torsional-flexural buckling force is 


$$
N_{c r T 1}=\frac{1}{r_{y 1}^{2}+r_{z 1}^{2}}\left(G I_{t 1}+\frac{\pi^{2} E I_{\omega 1}}{H^{2}}\right)
$$

and the corresponding reduced slenderness is

$$
\bar{\lambda}_{T 1}=\sqrt{\frac{A_{1} f_{y}}{N_{c r T 1}}}
$$

For the calculation of Eq.(27) the maximum value from $\bar{\lambda}_{z 1}$ and $\bar{\lambda}_{T 1}$ should be used.

\subsection{Bending and axial compression of the beam BC}

Similarly to Eqs (10) and (11) the stress constraints are as follows

$$
\frac{N_{2}}{\chi_{y 2} f_{y 1} A_{2}}+k_{y y 2} \frac{M_{C}}{\chi_{L T 2} f_{y 1} W_{y 2}} \leq 1
$$

and

$$
\frac{N_{2}}{\chi_{z 2} f_{y 1} A_{2}}+k_{z y 2} \frac{M_{C}}{\chi_{L T 2} f_{y 1} W_{y 2}} \leq 1
$$

The other formulae are similar to those given in Section 3.1, but with subscript 2 except the following:

$$
K_{2}=1.3
$$

and

$$
\begin{aligned}
& N_{2}=\frac{F}{2}+\frac{3 M_{p}}{2 H} \\
& C_{m y .02}=1+\left(\frac{\pi^{2} E I_{y 2} \delta_{x 2}}{L^{2} M_{C}}-1\right) \frac{N_{2}}{\chi_{y 2} f_{y 1} A_{2}} \\
& \delta_{x 2}=\frac{5 p L^{4}}{384 E I_{y 2}}-\frac{M_{p} L^{2}}{8 E I_{y 2}}
\end{aligned}
$$

In the above formulae the following geometric section characteristics should be calculated:

A - cross-sectional area

$I_{y}, I_{z}$ - moments of inertia about $y$ and $z$ axis, respectively

$W_{y}$ - section modulus about $y$ axis

$r_{y}$ and $r_{z}$ - radii of gyration about $y$ and $z$ axis, respectively

$I_{t}$ - torsional constant

$I_{\omega}$ - warping constant

and values of $t_{f c}$ and $z$ should be given (Eq. 18). 
These values are given in tabulated form for available UB and UC series produced by ARBED [9]. To ease the calculations, we have used approximate functions expressing the above characteristics in the function of section height $h$. To illustrate these approximate functions, the selected UB profiles are given in Table 1 with their heights and cross-sectional areas. These cross-sectional areas can be approximated by the following curve-fitting function

$$
A=-489.58486+14.366815 h+0.01824055 h^{2}\left(A \text { in } \mathrm{mm}^{2}, h \text { in } \mathrm{mm}\right)
$$

For instance, for UB 305x165x46.1 with $h=306.6 \mathrm{~mm}$ Eq.(41) gives $A=5629.96 \mathrm{~mm}^{2}$ instead of the actual value of $5875 \mathrm{~mm}^{2}$.

Table 1. Heights and cross-sectional areas of selected UB profiles according to ARBED [9

\begin{tabular}{ccc}
\hline UB profile & $h(\mathrm{~mm})$ & $A\left(\mathrm{~mm}^{2}\right)$ \\
\hline $152 \times 89 \times 16$ & 152.4 & 2032 \\
\hline $178 \times 102 \times 19$ & 177.8 & 2426 \\
\hline $203 \mathrm{z} 133 \times 25$ & 203.2 & 3197 \\
\hline $254 \times 146 \times 31$ & 251.4 & 3968 \\
\hline $254 \times 146 \times 37$ & 256.0 & 4717 \\
\hline $305 \times 165 \times 46.1$ & 306.6 & 5875 \\
\hline $356 \times 171 \times 57$ & 358.0 & 7256 \\
\hline $406 \times 178 \times 74$ & 409.4 & 8554 \\
\hline $457 \times 191 \times 74$ & 457.0 & 9463 \\
\hline $457 \times 191 \times 82$ & 460.0 & 10450 \\
\hline $610 \times 229 \times 113$ & 607.6 & 14390 \\
\hline $686 \times 254 \times 140$ & 683.5 & 17840 \\
\hline $838 \times 292 \times 194$ & 840.7 & 24680 \\
\hline
\end{tabular}

\section{Optimization characteristics and results}

The objective function to be minimized is the structural volume

$$
V=2 A_{1} H+A_{2} L
$$

The design constraints are described in Section 3. The unknown variables are the heights of column and beam rolled I-sections $h_{1}$ and $h_{2}$.

The Rosenbrock hillclimb algorithm [11] has been applied to find the optimum column and beam profiles, which minimize the volume (weight) and fulfil the design constraints. 

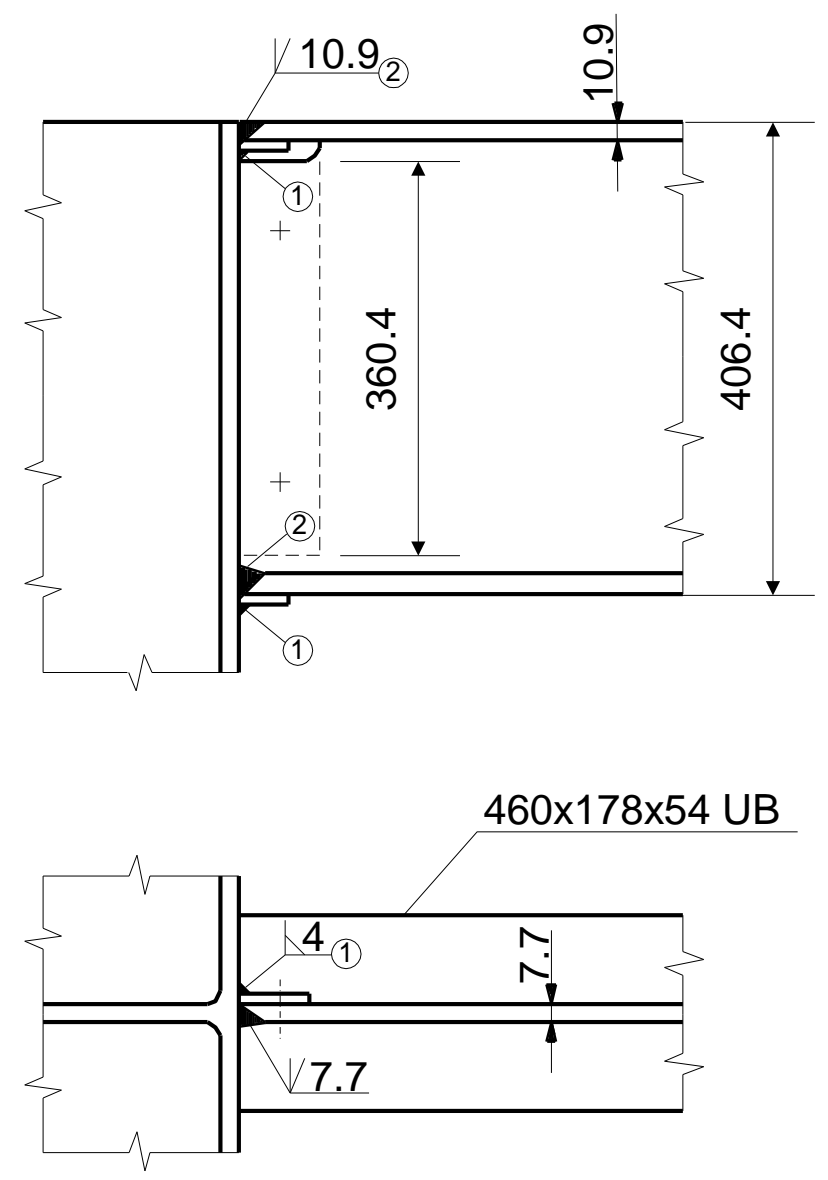

Figure 7 . The fully welded connection

\section{Cost calculation for frames with welded and bolted joints}

\subsection{British cost data}

The optimum design results in the following optimal British profiles:

Bolted version: columns UC203x203x52 beam UB406x178x54

Welded version: columns UC203×203x86 beam UB406x178x54

The moment capacity of the bolted connection is $162 \mathrm{kNm}$ [12], while the calculated bending moment in corner $\mathrm{C}$ is $76 \mathrm{kNm}$.

Costs of the frame with bolted connections:

Material cost: UB 406x178x54 $21 \mathrm{\iota} / \mathrm{m}=30.0 \$ / \mathrm{m}$, length $\mathrm{L}=7.62 \mathrm{~m}$, $228.6 \$$ UC $203 \times 203 \times 5220 \mathrm{t} / \mathrm{m}=28.6 \$ / \mathrm{m}$, length $2 \mathrm{H}=7.32 \mathrm{~m}$ $209.4 \$$ Material cost of bolts (100 bolts cost is $32 . .-\mathrm{t}) 16$ bolts $0.32 \times 16=5 \mathrm{~L}=$ 
Manufacturing costs: cutting of the beam ends (main) $25 \mathrm{~L}=35.8 \$$

Preparation (assembly) cost is calculated similarly than in the case of welded joint, with the same formula as follows

$K_{F 1}=k_{F} \Theta \sqrt{\kappa \rho V}=0.6 \times 2 \sqrt{3 \times 792.8}=58.5 \$$

since the total mass is $54.1 \times 7.62+52 \times 7.32=792.8 \mathrm{~kg}$

The cost of the bolted connection of medium type (endplate $25 \mathrm{~mm}$ thick, $200 \mathrm{~mm}$ wide, $410 \mathrm{~mm}$ deep, holing, welding to the end plate with fillet welds of leg size min 6 max $12 \mathrm{~mm}$ around the profile)

total manufacturing costs

$87 €=124.4 \$$

$218.7 \$$

Material and fabrication together

664.- $\$$

Costs of the frame with welded connections:

Material cost: UB 406x178x54 $21 \mathrm{t} / \mathrm{m}=30.0 \$ / \mathrm{m}, \mathrm{L}=7.62 \mathrm{~m}$, $.228 .6 \$$

UC $203 \times 203 \times 86 \quad 32 \mathrm{\iota} / \mathrm{m}=45.8 \$ / \mathrm{m} .2 \mathrm{H}=7.32 \mathrm{~m}$

Manufacturing costs: cutting of the beam ends (main) $25 \mathrm{t}=35.8 \$$

Welding $K_{W}=k_{F}\left(\Theta_{d} \sqrt{\kappa \rho V}+1.3 \sum_{i} \alpha_{P i} C_{W i} a_{W i}^{n} L_{W i}\right)$

$\rho V=7.62 \times 54.1+2 \times 3.66 \times 86.1=1042.5 \mathrm{~kg} / \mathrm{m}$

parts of the second member:

flanges $\quad 1.3 \times 0.5214 \times 10^{-3} \times 10.9^{2} \times 2 \times 177.7=28.6 \mathrm{~min}$

web $\quad 1.3 \times 2 \times 0.5214 \times 10^{-3} \times 7.7^{2} \times 360.4=14.5 \mathrm{~min}$

flange backing $1.3 \times 3 \times 0.7889 \times 10^{-3} \times 4^{2} \times 2 \times 177.7=17.5 \mathrm{~min}$

web backing $1.3 \times 2 \times 0.7889 \times 10^{-3} \times 4^{2} \times 360.4=11.8 \mathrm{~min}$

Total

$72.4 \min$

$K_{W}=0.6(2 \sqrt{3 \times 1042.5}+72.4)=110.5 \$$

Total manufacturing cost

$146.3 \$$

Material and manufacturing together

$709.9 \$$.

\subsection{South African cost data}

Tables 2-4 show the details of the cost calculation. 
Table 2. South African cost data

\begin{tabular}{|c|c|c|c|c|}
\hline Item & Units & Rand value & Dollar value & Reference \\
\hline UB $406 \times 178 \times 54$ & $\mathrm{R} / \mathrm{m}$ & 303,56 & 23,35 & Alert Steel [13] \\
\hline UC $203 \times 203 \times 52$ & $\mathrm{R} / \mathrm{m}$ & 298.1 & 22.9 & Alert Steel \\
\hline UC $203 \times 203 \times 86$ & $\mathrm{R} / \mathrm{m}$ & 493.6 & 37.9 & Alert Steel \\
\hline Plate $2.5 \times 1.2 \times 20$ & $\mathrm{R}$ & 2533.5 & 194.9 & Alert Steel \\
\hline Flat bar for back strips $40 \times 5$ & $\mathrm{R} / \mathrm{m}$ & 8.0 & 0.6 & Alert Steel \\
\hline Total Overhead, Labour, & $\mathrm{R} / \mathrm{h}$ & 180 & 22.5 & Spencer [14] \\
\hline \multicolumn{5}{|l|}{ Consumables \& Power } \\
\hline Cost of cutting plates : & & 1.08 & 0.08 & Alert steel \\
\hline \multicolumn{5}{|l|}{ Material cost } \\
\hline Drilling of M20 holes & R/hole & 5 & 0.38 & Jan Brand UP [15] \\
\hline 8.8 grade M20bolts & R each & 6.97 & 0.54 & Screw Man [16] \\
\hline Cost of cutting R180/h, $0.17 \mathrm{~min} / 25 \mathrm{~mm}$ & $\mathrm{R} / \mathrm{mm}$ & 0.0204 & & \\
\hline
\end{tabular}

Table 3. Calculation of costs $(\mathrm{R}=\mathrm{Rand})$ for rigid structure

\begin{tabular}{|c|c|c|c|c|c|c|c|}
\hline Item & $\mathrm{R} / \mathrm{m}$ & M & $\mathrm{R}$ & & & $\mathrm{R}$ & $\$$ \\
\hline \multicolumn{8}{|l|}{ Price } \\
\hline UB406x178x54 & 303.6 & 7.62 & 2313.1 & & & & \\
\hline UC203x203x86 & 493.6 & 7.32 & 3613.2 & & & & \\
\hline Str40x5 flanges & 8.0 & 0.7 & 5.7 & & & & \\
\hline$\underline{\text { Str } 40 \times 5 \text { webs }}$ & 8.0 & 0.7 & 5.8 & & & & \\
\hline$\underline{\text { Total }}$ & & & 5937.8 & & & 5938 & 742.2 \\
\hline Mass & $\mathrm{Kg} / \mathrm{m}$ & $\mathrm{M}$ & $\mathrm{Kg}$ & $\min$ & & & \\
\hline UB & 54.1 & 7.62 & 412.2 & & & & \\
\hline $\mathrm{UC}$ & 86.1 & 7.32 & 630.3 & & & & \\
\hline Total & & & 1042.5 & & & & \\
\hline Assembly \& tacking time & & & & 111.8 & & & \\
\hline Welding time & $\alpha_{p}$ & $C_{\mathrm{w}}$ & $a_{w}{ }^{2}$ & $L$ & $\min$ & & \\
\hline flanges & 1 & 0.000521 & 118.8 & $2 \times 177.7$ & 28.6 & & \\
\hline webs & 2 & 0.000521 & 57.8 & $2 \times 360.4$ & 14.5 & & \\
\hline flange strips & 3 & 0.000789 & 16 & $2 \times 177.7$ & 17.5 & & \\
\hline Web strips & 2 & 0.000789 & 16 & $2 \times 360.4$ & 11.8 & & \\
\hline$\underline{\text { Total }}$ & & & & & 72.4 & & \\
\hline Total welding cost & & & & $\mathrm{R}$ & & 532.9 & 66.6 \\
\hline Cutting & length & $\min$ & $\mathrm{R} / \mathrm{min}$ & $\mathrm{R}$ & & & \\
\hline UB & 402.6 & 2.7 & 3 & 8.2 & & & \\
\hline $\mathrm{UC}$ & 444.6 & 3.0 & 3 & 9.1 & & & \\
\hline Total cutting & & & & 17.3 & & & \\
\hline Total manufacturing cost & & & & & & 550.2 & 68.8 \\
\hline Total manufacturing and material & & & & & & 6488.2 & 810.9 \\
\hline
\end{tabular}


Table 4. Calculation of cost for semi-rigid structure

\begin{tabular}{|c|c|c|c|c|c|c|c|}
\hline Item & $\mathrm{R} / \mathrm{m}$ & $\mathrm{m}$ & $\mathrm{R}$ & & & $\mathrm{R}$ & $\$$ \\
\hline Bolts & 7.0 & 16 & 111,5 & & & & \\
\hline UB406X178X54 & 303.6 & 7,6 & 2313,1 & & & & \\
\hline UC203X203X52 & 298.1 & 7,3 & 2182,2 & & & & \\
\hline$\underline{\text { Plates } 200 X 25}$ & 254.5 & 0,8 & 208,7 & & & & \\
\hline$\underline{\text { Total material }}$ & & & 4815,6 & & & 4843.5 & 605.4 \\
\hline Manufacturing & $\mathrm{Mm}$ & $\mathrm{min} / \mathrm{mm}$ & $\mathrm{R} / \mathrm{min}$ & $\mathrm{R}$ & & & \\
\hline \multicolumn{8}{|l|}{ Cutting } \\
\hline Plate & 400 & 0,0068 & 3 & 8.2 & & & \\
\hline Beam & 402.6 & 0,0068 & 3 & 8.2 & & & \\
\hline Columns & 412.4 & 0,0068 & 3 & 8.4 & & & \\
\hline Total cutting & & & & 24.8 & & & \\
\hline Assembly \& Tacking & $\mathrm{kg} / \mathrm{m}$ & $\mathrm{m}$ & $\mathrm{kg}$ & $\min$ & & & \\
\hline UB & 54.1 & 7.6 & 412.2 & & & & \\
\hline End plates & 39.2 & 0.8 & 32.1 & & & & \\
\hline$\underline{\text { Total }}$ & & & 444.4 & 73.0 & & & \\
\hline Welding & $\alpha_{p}$ & $C_{\mathrm{w}}$ & $a_{w}{ }^{2}$ & $L$ & $\min$ & & \\
\hline Flanges to plate & 1 & 0.000789 & 36.0 & $4 \times 177.7$ & 26.3 & & \\
\hline Webs to plate & 2 & 0.000789 & 36.0 & $2 \times 360.4$ & 53.3 & & \\
\hline Total welding cost & & & & & & 238.4 & 29.8 \\
\hline \multicolumn{8}{|l|}{ Drilling } \\
\hline & R/hole & nr. Holes & & & $\mathrm{R}$ & & \\
\hline & 5 & 16 & & & 80 & & 10 \\
\hline \multicolumn{8}{|l|}{ Assembly \& bolting time } \\
\hline$\underline{\mathrm{UC}}$ & 52 & 7.3 & 380.6 & & & & \\
\hline UB & 54.1 & 7.6 & 412.2 & & & & \\
\hline$\underline{\text { End plates }}$ & 39.2 & 0.8 & 32.1 & & & & \\
\hline Total & & & 825.0 & 99.5 & & & \\
\hline Assembly \& bolting cost & & & & & 196.3 & & 24.5 \\
\hline Total manufacturing & & & & & & 514.4 & 64.3 \\
\hline Total for bolted connection & & & & & & 5277.8 & 669.7 \\
\hline
\end{tabular}

\section{Conclusion}

The detailed cost calculations show that according to British data, the bolted connection is $7 \%$ cheaper than the welded one. This difference has two components: the difference between material costs and the difference between fabrication costs. 
According to the South African data, the bolted connection is about $14 \%$ cheaper than the welded one. The material cost is however more expensive and manufacturing is cheaper than the British costs.

It can be concluded that the bolted connections are more economic than the fully welded ones. The calculation is very sensitive to the given data concerning the manufacturing times. These data are different in various companies and countries as well. The scatter can be relatively large between solutions, but making the calculation for a given frame using actual time and cost data, one can get the result and can choose the type of connection.

Since the rotational stiffness of semi-rigid bolted connections is smaller than that of welded ones, the maximum bending moment in an unbraced frame structure is smaller and the beam section can be smaller. The difference between the fabrication costs is significant as well. The disadvantage of bolted connections is the very complicated calculation of rotational stiffness. This causes difficulties in the optimum design of frames with semi-rigid beam-to-column connections. Fabricators prefer welded connections if they are fabricated in workshop, on the other hand, on site, bolted joints are usually cheaper.

Table 4. Summary of costs in $\$$

\begin{tabular}{llcc}
\hline Joint & Cost of & Great Britain & South Africa \\
\hline \multirow{2}{*}{ Welded } & Material & 563.6 & 742.00 \\
& Manufacturing & 146.3 & 109.00 \\
& Total & 709.9 & 851.00 \\
\hline \multirow{2}{*}{ Bolted } & Material & 445.3 & 605.4 \\
& Manufacturing & 218.7 & 64.3 \\
& Total & 664.0 & 669.7 \\
\hline
\end{tabular}

\section{Acknowledgement}

The research work was supported by the Hungarian Scientific Research Foundation grants OTKA T38058 and T37941. The project was also supported by the Hungarian-South African Intergovernmental S\&T co-operation program. The Hungarian partner is the Ministry of Education, R\&D Deputy Undersecretary of State, the South African partner is the Foundation for Research Development.

\section{References}

[1] Eurocode 3. Part 1.8. 2002. Design of joints. 
[2] Witteveen,J., Stark,J.W.B., Bijlaard,F.S.K. \& Zoetemeijer,P.: Welded and bolted beam-tocolumn connections. J. Struct. Division Proc. ASCE 108: 1982 (ST2), 433-455.

[3] Farkas,J., Jármai,K. \& Visser-Uys,P. Cost comparison of bolted and welded frame joints. Welding in the World 47: 2003 (1/2) 12-18.

[4] Farkas,J. \& Jármai,K. Economic design of metal structures. Rotterdam, Millpress, 2003.

[5] Al-Salloum,Y.A. \& Almusallam,T.H. Optimality and safety of rigidly and flexibly jointed steel frames. J.Construct.Steel Res. 35: 1995, 189-215.

[6] Simões,L.M.C. Optimization of frames with semi-rigid connections. Computers and Structures 60: 1996 (4) 531-539.

[7] Kameshki,E.S. \& Saka, M.P. Genetic algorithm based optimum design of nonlinear planar steel frames with various semi-rigid connections. J. Constructional Steel Research 59:2003, 109-134.

[8] Steenhuis,M., Weynand,K. \& Gresnigt,A.M. Strategies for economic design of unbraced steel frames. J. Constructional Steel Research 46: 1998 (1-3). Paper No.60. CD-ROM.

[9] ARBED: Profil. Ed. 3-2001.

[10] Eurocode 3: Design of steel structures. Part 1-1: General structural rules. European Prestandard prEN 1993-1-1: 2002. Brussels, European Committee for Standardisation.

[11] Farkas,J. \& Jármai,K.: Analysis and optimum design of metal structures. Balkema, RotterdamBrookfield, 1997.

[12] Joints in steel construction. Moment connections. The Steel Construction Institute Publ. No. 207. Ascot, UK. 1995.

[13] ALERT STEEL Pretoria. Price list January 2002.

[14] Spencer Irving. South African Institute of Steel Construction. Personal communication April 2002.

[15] Brand,J. Technical instructor. University of Pretoria. Personal communication. April 2002.

[16] The Screw-man (PTA) (PTY) LTD. Personal communication. April 2002 